Article

\title{
The Use of Essential Oil and Hydrosol Extracted from Satureja hellenica for the Control of Meloidogyne incognita and M. javanica
}

\author{
Iro Pardavella ${ }^{1}$, Eleni Nasiou ${ }^{1}$, Dimitra Daferera ${ }^{2}$, Panayiotis Trigas ${ }^{3}{ }^{[}$and \\ Ioannis Giannakou ${ }^{1, *}$ \\ 1 Laboratory of Agricultural Zoology and Entomology, Department of Science of Crop Production, \\ Agricultural University of Athens, Iera Odos 75, 11855 Athens, Greece; iro.pardavella@gmail.com (I.P.); \\ lenanasiou@gmail.com (E.N.) \\ 2 Laboratory of Chemistry, Department of Food Science and Human Nutrition, Agricultural University of \\ Athens, Iera Odos 75, 11855 Athens, Greece; daferera@aua.gr \\ 3 Laboratory of Systematic Botany, Department of Science of Crop Production, Agricultural University of \\ Athens, Iera Odos 75, 11855 Athens, Greece; trigas@aua.gr \\ * Correspondence: IGiannakou@aua.gr; Tel.: +30-21-0529-4571
}

Received: 17 June 2020; Accepted: 3 July 2020; Published: 7 July 2020

\begin{abstract}
Essential oil (EO) and hydrosol (HL) isolated from an indigenous plant species Satureja hellenica were evaluated against Meloidogyne incognita and M. javanica. Particularly, the activity of extracts on a second stage juvenile's (J2s) motility, the hatching of J2s from eggs, egg differentiation and the effect on J2s in soil were tested. A paralysis of $100 \%$ of the J2s of both species was recorded after $96 \mathrm{~h}$ of immersion in the essential oil, at a dose of $2000 \mu \mathrm{L} / \mathrm{L}$. At the same dose, the percentage of paralyzed J2s after $48 \mathrm{~h}$ of immersion was more than $80 \%$, for both Meloidogyne species. The use of hydrosol has shown encouraging results only in the dilution of $50 \%$, where for both Meloidogyne species tested, the percentage of paralyzed J2s was more than $70 \%$ after $48 \mathrm{~h}$ of immersion, while the percentage was increased to $90 \%$ after $96 \mathrm{~h}$ of immersion. Egg differentiation was ceased after immersion, either in EO or HL. However, this decrease in egg differentiation was evident only at higher concentrations of $\mathrm{EO}$ and at the highest HL dilution $(0.5 v / v)$. The hatching of M. incognita $\mathrm{J} 2 \mathrm{~s}$ was decreasing as the dose was increasing. The lowest numbers of hatched J2s were recorded at the doses of 2000 and $4000 \mu \mathrm{L} / \mathrm{L}$. A clear reduction in M. javanica J2s hatching was observed as the dose was increased to $250 \mu \mathrm{L} / \mathrm{L}$, a fact constantly observed as the dose was increasing up to $4000 \mu \mathrm{L} / \mathrm{L}$. Lower numbers of nematodes were recorded in roots grown in infested soil after the application of EO or HL at the highest doses. The EO of S. hellenica is characterized by the presence of p-cymene $(27.46 \%)$ and carvacrol $(23.25 \%)$, and in a lesser extent of other constituents, such as borneol $(6.79 \%)$, carvacrol methylether (6.77\%), $\gamma$-terpinene (4.63\%) and 4-terpineol (3.65\%). Carvacrol was the major constituent found in the HL (50.12\%), followed by borneol and 4-terpineol (20.42 and $6.72 \%$, respectively).
\end{abstract}

Keywords: Meloidogyne incognita; M. javanica; Cuminum cyminum; essential oil; hydrosol; root-knot management

\section{Introduction}

Plant parasitic nematodes are the most destructive group of plant pathogens worldwide, and their control is extremely challenging [1]. Many crops all over the world can be infested by nematodes, creating yield losses of over a billion Euros annually [2]. In the recent past years, a lot of nematicides have been widely used to suppress the root-knot nematodes (RKN) populations in vegetable production. 
However, some nematicides, such as methyl bromide, have been banned, due to their adverse effect on the environment. Nematodes management is based on cultural practices, crop rotation, resistant cultivars or root stocks and the use of a limited number of synthetic chemical nematicides. However, for the ones that are still used, their repetitive application reduced their persistence and efficacy due to enhanced degradation [3,4]. A lot of research has been undertaken to find new molecules which are effective against plant parasitic nematodes [5-10]. Plant derived phytochemicals can be used as pesticides themselves, or they can serve as model compounds for the agrochemical industry [6]. Towards this, plant essential oils (EOs) and their components have been repeatedly tested against sedentary and migratory endoparasitic nematodes [6]. Plants produce a set of volatile organic compounds as a defense mechanism against damage by pests and pathogens. EOs are natural volatile substances extracted from a wide range of plants belonging to different botanical families. Essential oils consist of a mixture of terpenoids [11]. Their chemical composition is not stable amongst the plant species and varieties, or even amongst the phenological stages of the plant. Although EOs have long been investigated, not much attention has been paid to hydrosols, which are by-products derived during hydrodistillation. Hydrosols derived from three Lamiaceae species showed an important adverse effect on the settling behavior of Myzus persicae [12]. Traka et al. [13] reported that hydrosols derived from Ocinum basilicum and Ruta chalepensis presented an important effect on the mortality of Aphis gossypii and Tetranychus urticae. Terpenes constituent of EOs are responsible for the characteristic aroma and odor of each plant, because of the volatile compounds that they contain. The presence of volatile terpenes provides EOs with antimicrobial, antifungal [14], antioxidant [15], insecticidal [16,17] and nematicidal properties [18]. A large number of EOs and their components have been found to have nematicidal activity against pinewood (Bursaphelenchus xylophilus) and root-knot nematodes (Meloidogyne spp.) $[6,19,20]$.

The objective of this study was the evaluation of the nematicidal activity of the essential oil and hydrosol obtained from an indigenous species Satureja hellenica, and their correlation to the chemical composition.

\section{Results}

\subsection{Chemical Composition of Essential Oil and Hydrosol}

The data in Table 1 show the identified compounds in order of their elution from the TR-5MS capillary column, the relative retention indices (RRI), and the compounds' relative percentages in the total composition of the EO and hydrosol. Thirty-two constituents were identified from the EO, while 18 constituents were recorded in the hydrosol. The EO is characterized by the presence of $p$-cymene $(27.46 \%)$ and carvacrol $(23.25 \%)$, and in a lesser extent of other constituents such as borneol $(6.79 \%)$, carvacrol methylether $(6.77 \%), \gamma$-terpinene $(4.63 \%)$ and 4 -terpineol (3.65\%). Carvacrol was the major constituent found in the hydrosol (50.12\%) followed by borneol and 4-terpineol (20.42 and $6.72 \%$, respectively).

\subsection{Nematicidal Effect of Essential Oil and Hydrosol}

The numbers of dead M. incognita and M. javanica second stage juveniles (J2s), as affected by the different doses of the essential oil, are presented in Tables 2 and 3, respectively. The percentage of dead $\mathrm{J} 2 \mathrm{~s}$ increased as the exposure time increased. The essential oil killed $100 \%$ of the J2s of both species after $96 \mathrm{~h}$ of immersion at a dose of $2000 \mu \mathrm{L} / \mathrm{L}$. At the same dose, the percentage of dead J2s after $48 \mathrm{~h}$ of immersion was more than $80 \%$, for both Meloidogyne species. 
Table 1. Chemical composition of the essential oil and hydrosol of Satureja hellenica.

\begin{tabular}{|c|c|c|c|c|}
\hline No & RRI * & Compound & S. hellenica e.o. & S. hellenica Hydrosol \\
\hline 1 & 940 & $\alpha$-Pinene & 1.5 & $-\#$ \\
\hline 2 & 948 & Camphene & 1.3 & - \\
\hline 3 & 979 & 1-Octen-3-ol & - & 1.6 \\
\hline 4 & 981 & $\beta$-Myrcene & 1.0 & - \\
\hline 5 & 999 & 3-Octanol & - & 0.3 \\
\hline 6 & 1014 & $\alpha$-Terpinene & 1.1 & - \\
\hline 7 & 1024 & $p$-Cymene & 27.5 & - \\
\hline 8 & 1057 & $\gamma$-Terpinene & 4.6 & - \\
\hline 9 & 1075 & cis-Sabinene hydrate & 2.4 & 4.6 \\
\hline 10 & 1083 & Terpinolene & 0.4 & - \\
\hline 11 & 1082 & cis-Linalool oxide & - & 0.7 \\
\hline 12 & 1100 & Linalool & 0.6 & 0.7 \\
\hline 13 & 1102 & trans-Sabinene hydrate & 0.4 & 2.5 \\
\hline 14 & 1136 & 1-Terpineol & 0.3 & - \\
\hline 15 & 1143 & cis-2-Pinanol & 0.6 & 1.3 \\
\hline 16 & 1152 & Camphor & 0.5 & 1.2 \\
\hline 17 & 1179 & Borneol & 6.8 & 20.4 \\
\hline 18 & 1183 & 4-Terpineol & 3.6 & 6.7 \\
\hline 19 & 1188 & $p$-Cymen-8-ol & 0.3 & 2.8 \\
\hline 20 & 1195 & $\alpha$-Terpineol & 0.6 & 1.9 \\
\hline 21 & 1204 & cis-Dihydrocarvone & 0.2 & - \\
\hline 22 & 1223 & Coahuilensol methyl ether & - & 0.2 \\
\hline 23 & 1232 & Thymol methylether & 1.4 & - \\
\hline 24 & 1243 & Carvacrol methylether & 6.8 & 0.5 \\
\hline 25 & 1270 & Geranial & 0.1 & - \\
\hline 26 & 1292 & Thymol & 0.3 & - \\
\hline 27 & 1299 & Carvacrol & 23.3 & 50.1 \\
\hline 28 & 1348 & Thymol acetate & - & 0.3 \\
\hline 29 & 1354 & Eugenol & - & 0.2 \\
\hline 30 & 1418 & (E)-Caryophyllene & 3.5 & 0.2 \\
\hline 31 & 1438 & Aromadendrene & 0.4 & - \\
\hline 32 & 1457 & $\alpha$-Humulene & 0.2 & - \\
\hline 33 & 1491 & Viridiflorene & 0.2 & \\
\hline 34 & 1495 & Bicyclogermacrene & 0.3 & \\
\hline 35 & 1507 & $\beta$-Bisabolene & 3.5 & - \\
\hline 36 & 1575 & Spathulenol & 1.4 & 0.4 \\
\hline 37 & 1580 & Caryophyllene oxide & 2.7 & 0.3 \\
\hline \multirow[t]{7}{*}{38} & 1652 & $\alpha$-Eudesmol & 0.2 & 0.1 \\
\hline & & Total (\%) & 98.0 & 97.0 \\
\hline & & Monoterpene Hydrocarbons (MH) & 37.4 & - \\
\hline & & Oxygenated Monoterpenes (OM) & 48.2 & 93.7 \\
\hline & & Sesquiterpene Hydrocarbons (SH) & 8.1 & 0.2 \\
\hline & & Oxygenated Sesquiterpenes (OS) & 4.3 & 0.8 \\
\hline & & Others & - & 2.3 \\
\hline
\end{tabular}

* RRI: Relative Retention Index obtained on TR-5MS column using a series of $n$-alkanes (C8-C24). ${ }^{\#}$ Not detected.

Table 2. Effect of essential oil on the motility of M. incgonita second stage juveniles (J2s) after immersion in test solutions, at the doses of $0,62.5,125,250,500,1000,2000$ and $4000 \mu \mathrm{L} / \mathrm{L}$, for 24,48 and $96 \mathrm{~h}$.

\begin{tabular}{cccc}
\hline & \multicolumn{3}{c}{ Exposure Time (h) } \\
\cline { 2 - 4 } Dose $(\mu \mathrm{L} / \mathrm{L})$ & $\mathbf{2 4}$ & $\mathbf{4 8}$ & $\mathbf{9 6}$ \\
\cline { 2 - 4 } & Dead J2s (\%) & Dead J2s (\%) & Dead J2s (\%) \\
\hline 0 & $0.0 \mathrm{~d}$ & $2.6 \mathrm{~d}$ & $10.4 \mathrm{e}$ \\
62.5 & $0.0 \mathrm{~d}$ & $2.0 \mathrm{~d}$ & $25.3 \mathrm{~d}$ \\
125 & $0.0 \mathrm{~d}$ & $4.3 \mathrm{~d}$ & $25.7 \mathrm{~d}$ \\
250 & $0.5 \mathrm{~d}$ & $7.5 \mathrm{~d}$ & $21.4 \mathrm{~d}$ \\
500 & $1.1 \mathrm{~d}$ & $30.6 \mathrm{c}$ & $56.6 \mathrm{c}$ \\
1000 & $7.7 \mathrm{c}$ & $38.5 \mathrm{c}$ & $85.6 \mathrm{~b}$ \\
2000 & $31.1 \mathrm{~b}$ & $81.2 \mathrm{~b}$ & $100 \mathrm{a}$ \\
4000 & $99.1 \mathrm{a}$ & $100 \mathrm{a}$ & $100 \mathrm{a}$ \\
\hline
\end{tabular}


Table 3. Effect of essential oil on the motility of $M$. javanica J2s after immersion in test solutions at the doses of $0,62.5,125,250,500,1000,2000$ and $4000 \mu \mathrm{L} / \mathrm{L}$ for 24,48 and $96 \mathrm{~h}$.

\begin{tabular}{cccc}
\hline \multirow{2}{*}{ Dose $(\mu \mathrm{L} / \mathrm{L})$} & \multicolumn{3}{c}{ Exposure Time (h) } \\
\cline { 2 - 4 } & $\mathbf{2 4}$ & $\mathbf{4 8}$ & $\mathbf{9 6}$ \\
\cline { 2 - 4 } & Dead J2s (\%) & Dead J2s (\%) & Dead J2s (\%) \\
\hline 0 & $0.3 \mathrm{~d}$ & $1.1 \mathrm{~d}$ & $12.4 \mathrm{~d}$ \\
62.5 & $3.7 \mathrm{~d}$ & $6.9 \mathrm{~cd}$ & $23.2 \mathrm{~cd}$ \\
125 & $3.6 \mathrm{~d}$ & $5.2 \mathrm{~cd}$ & $31.5 \mathrm{c}$ \\
250 & $2.4 \mathrm{~d}$ & $7.0 \mathrm{c}$ & $22.7 \mathrm{~cd}$ \\
500 & $4.6 \mathrm{~d}$ & $13.1 \mathrm{c}$ & $46.2 \mathrm{c}$ \\
1000 & $12.7 \mathrm{c}$ & $35.4 \mathrm{~b}$ & $82.5 \mathrm{~b}$ \\
2000 & $48.5 \mathrm{~b}$ & $86.2 \mathrm{a}$ & $100 \mathrm{a}$ \\
4000 & $90.1 \mathrm{a}$ & $98.9 \mathrm{a}$ & $100 \mathrm{a}$ \\
\hline
\end{tabular}

The percentage of dead M. incognita and M. javanica J2s, as affected by the different dilutions of the hydrosol (HL), is presented in Tables 4 and 5, respectively. The hydrosol gave encouraging results only in the dilution of $0.5 \mathrm{v} / \mathrm{v}$, where for both species, the percentage of dead J2s was more than $70 \%$ after $48 \mathrm{~h}$ of immersion. At the same dilution, the percentage was more than $90 \%$ after $96 \mathrm{~h}$ of immersion for both Meloidogyne species. In both nematode species, lower HL concentrations of S. hellenica did not affect the motility of juveniles after immersion, either for 24 or $48 \mathrm{~h}$. However, a decrease of J2s motility was observed after $96 \mathrm{~h}$ immersion amongst the low concentrations of the HL and the control for both Meloidogyne species.

Table 4. Effect of hydrosol on the motility of $M$. incognita J2s after immersion in test solutions at the dilutions $0,0.01,0.02,0.05,0.1,0.2$ and $0.5 v / v$ for 24,48 and $96 \mathrm{~h}$.

\begin{tabular}{cccc}
\hline & \multicolumn{3}{c}{ Exposure Time (h) } \\
\cline { 2 - 4 } Dilution $(v / v)$ & $\mathbf{2 4}$ & $\mathbf{4 8}$ & $\mathbf{9 6}$ \\
\cline { 2 - 4 } & Dead J2s (\%) & Dead J2s (\%) & Dead J2s (\%) \\
\hline 0 & $0.0 \mathrm{~b}$ & $0.5 \mathrm{~b}$ & $1.9 \mathrm{c}$ \\
0.01 & $0.6 \mathrm{~b}$ & $1.7 \mathrm{~b}$ & $5.2 \mathrm{bc}$ \\
0.02 & $0.5 \mathrm{~b}$ & $2.6 \mathrm{~b}$ & $7.7 \mathrm{~b}$ \\
0.05 & $1.0 \mathrm{~b}$ & $1.9 \mathrm{~b}$ & $11.6 \mathrm{~b}$ \\
0.1 & $0.8 \mathrm{~b}$ & $1.2 \mathrm{~b}$ & $8.3 \mathrm{~b}$ \\
0.2 & $0.2 \mathrm{~b}$ & $1.0 \mathrm{~b}$ & $8.3 \mathrm{~b}$ \\
0.5 & $13.1 \mathrm{a}$ & $75.9 \mathrm{a}$ & $93.3 \mathrm{a}$ \\
\hline
\end{tabular}

Table 5. Effect of hydrosol on the motility of $M$. javanica J2s after immersion in test solutions at the dilutions $0,0.01,0.02,0.05,0.1,0.2$ and $0.5 v / v$, for 24,48 and $96 \mathrm{~h}$.

\begin{tabular}{cccc}
\hline & \multicolumn{3}{c}{ Exposure Time (h) } \\
\cline { 2 - 4 } Dilution $(v / v)$ & $\mathbf{2 4}$ & $\mathbf{4 8}$ & $\mathbf{9 6}$ \\
\cline { 2 - 4 } & Dead J2s (\%) & Dead J2s (\%) & Dead J2s (\%) \\
\hline 0 & $0.3 \mathrm{~b}$ & $0.8 \mathrm{~b}$ & $6.5 \mathrm{c}$ \\
0.01 & $0.9 \mathrm{~b}$ & $2.0 \mathrm{~b}$ & $14.0 \mathrm{bc}$ \\
0.02 & $0.8 \mathrm{~b}$ & $3.0 \mathrm{~b}$ & $18.4 \mathrm{~b}$ \\
0.05 & $1.0 \mathrm{~b}$ & $1.6 \mathrm{~b}$ & $13.7 \mathrm{bc}$ \\
0.1 & $1.4 \mathrm{~b}$ & $2.4 \mathrm{~b}$ & $22.8 \mathrm{~b}$ \\
0.2 & $2.5 \mathrm{~b}$ & $6.8 \mathrm{~b}$ & $28.8 \mathrm{~b}$ \\
0.5 & $46.1 \mathrm{a}$ & $79.7 \mathrm{a}$ & $96.4 \mathrm{a}$ \\
\hline
\end{tabular}




\subsection{Effect of EO and HL on Egg Differentiation}

The results of the effect of the essential oil on egg differentiation, as means of the two experiments, are shown in Figure 1 for both species. No significant differences were recorded among the different concentrations of the EO for $M$. incognita. However, by increasing the concentration to $250 \mu \mathrm{L} / \mathrm{L}$, a significant reduction of the differentiated eggs was observed compared to the control. A different pattern was observed when $M$. javanica was used. The essential oil substantially inhibited eggs differentiation when tested at doses of 500, 1000, 2000 and $4000 \mu \mathrm{L} / \mathrm{L}$. Egg differentiation was also inhibited when undifferentiated eggs were treated with lower doses of EO (125 and $250 \mu \mathrm{L} / \mathrm{L})$.

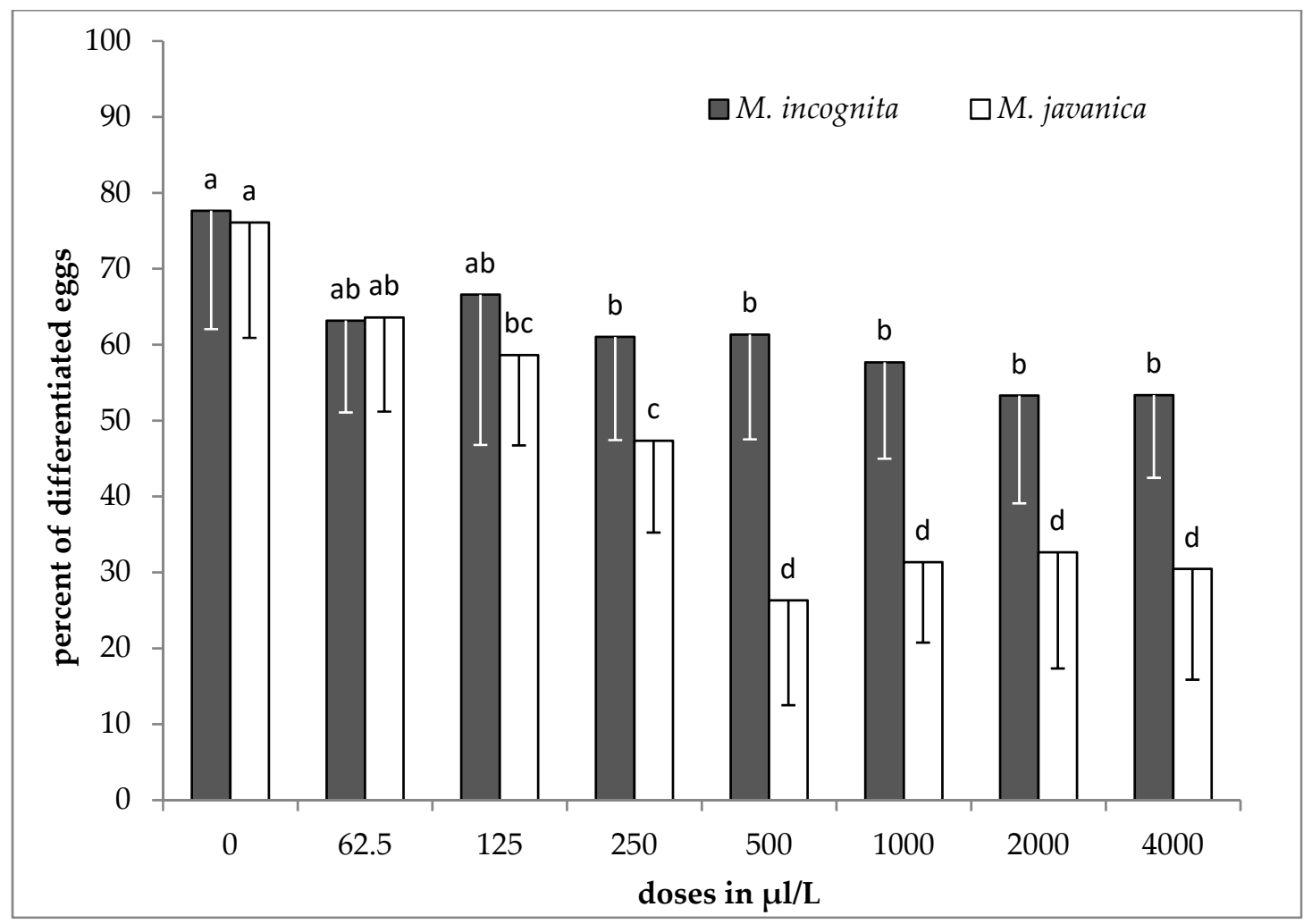

Figure 1. Effect of essential oil on the differentiation of $M$. incognita and $M$. javanica eggs after immersion in test solutions, at the doses of $0,62.5,125,250,500,1000,2000$ and $4000 \mu \mathrm{L} / \mathrm{L}$ for 28 days. Bars with the same color followed by the same letter are not significantly different. Error bars represent the standard deviation of mean.

No significant differences were recorded among the different doses of $S$. hellenica HL for both species tested, except that of $0.5 v / v$, which was significantly different to the control, and also to the lower doses (Figure 2).

\subsection{Hatching Inhibition as Affected by the Presence of EO and HL}

The results of the effect of the essential oil on hatching inhibition, as means of the two experiments, are presented in Figure 3. The effect of the essential oil on hatching of J2s was related to different doses after 35 days exposure for both species. The hatching of $M$. incognita J2s was decreasing as the dose was increasing. The lowest numbers of hatched J2s were recorded at the doses of 2000 and $4000 \mu \mathrm{L} / \mathrm{L}$. A clear reduction in M. javanica juveniles hatching was observed, as the dose was increased to $250 \mu \mathrm{L} / \mathrm{L}$, a fact constantly observed as the dose was increasing up to $4000 \mu \mathrm{L} / \mathrm{L}$.

No significant differences were recorded for both species among the control and the doses up to $0.1 v / v$ of hydrosol to water (Figure 4). A reduction in J2s hatching was observed when the dose of hydrosol was increased to $0.2 v / v$, and a further reduction was evident by increasing the dose to $0.5 v / v$. 


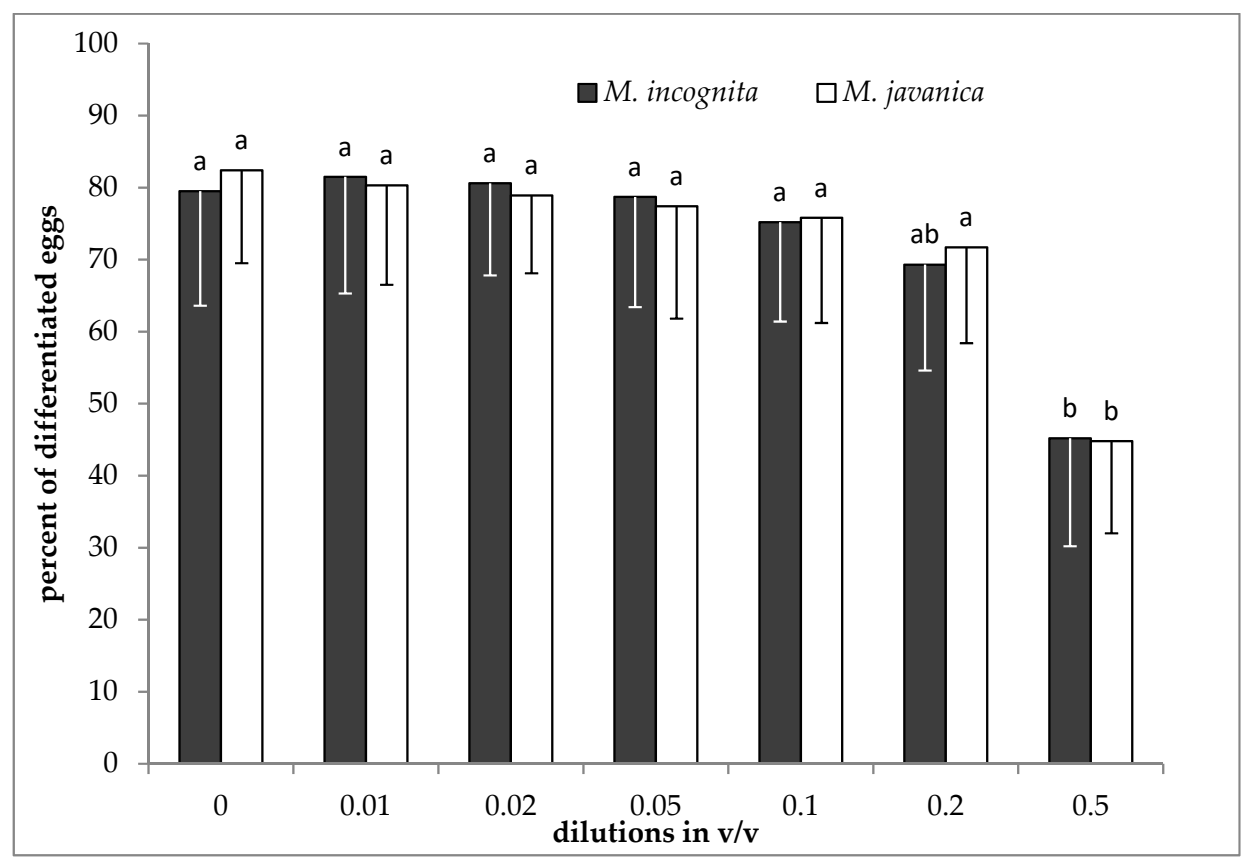

Figure 2. Effect of hydrosol on the differentiation of M. incognita and M. javanica eggs after immersion in test solutions at the doses of $0,0.01,0.02,0.05,0.1,0.2$ and $0.5 v / v$, for 28 days. Bars with the same color followed by the same letter are not significantly different. Error bars represent the standard deviation of mean.

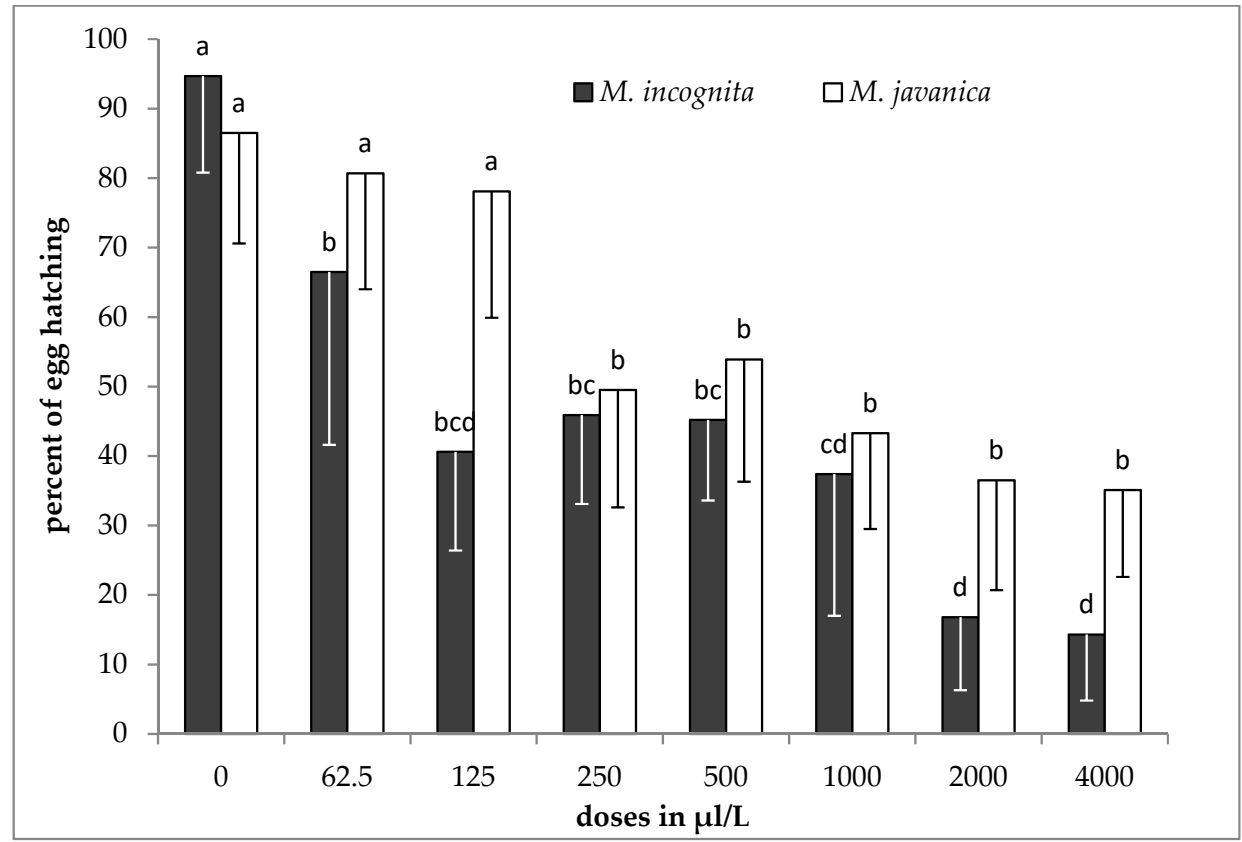

Figure 3. Effect of essential oil on hatching of $M$. incognita and M. javanica J2s after immersion in test solutions at the doses of $0,62.5,125,250,500,1000$ and $2000 \mu \mathrm{L} / \mathrm{L}$ for 35 days. Bars with the same color followed by the same letter are not significantly different. Error bars represent the standard deviation of mean. 


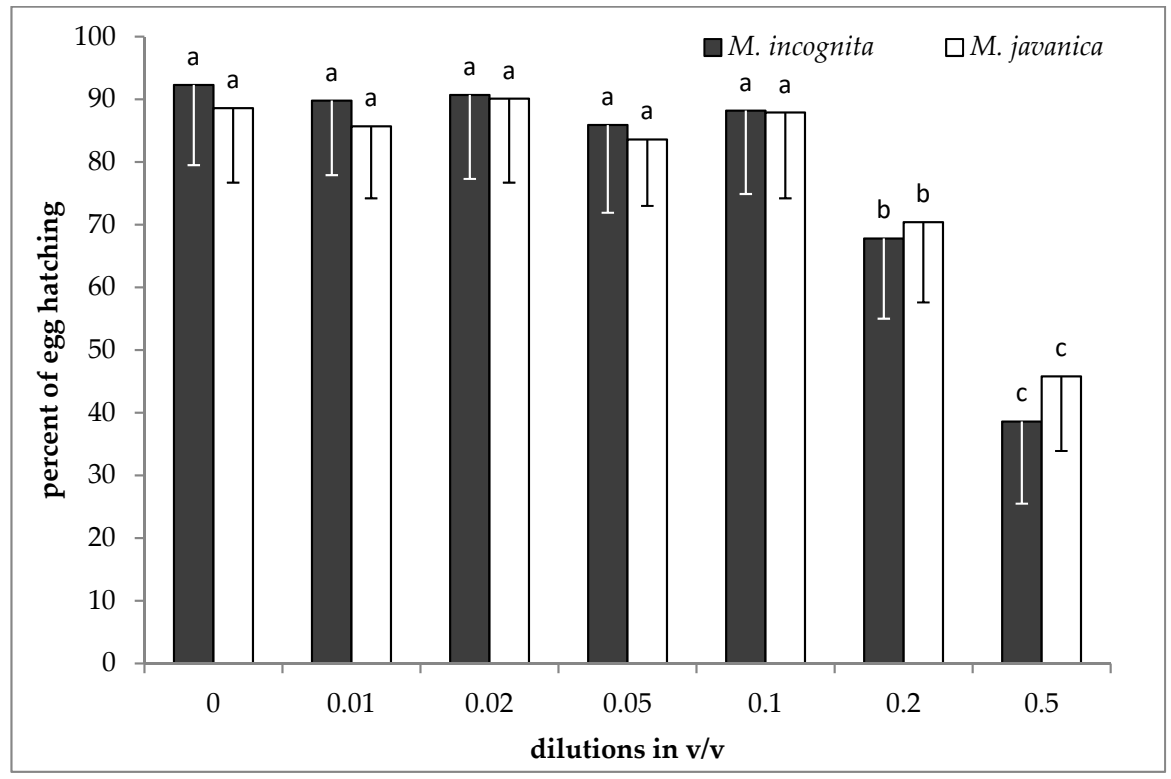

Figure 4. Effect of hydrosol on hatching of $M$. incognita and $M$. javanica $\mathrm{J} 2 \mathrm{~s}$ after immersion in test solutions, at the doses of $0,0.01,0.02,0.05,0.1,0.2$ and $0.5 v / v$ for 28 days. Bars with the same color followed by the same letter are not significantly different. Error bars represent the standard deviation of mean.

\subsection{Effect of EO and HL on Juveniles in Soil}

No significant differences were recorded for the number of females per gram of root, either for M. incognita or M. javanica, at doses up to $1000 \mu \mathrm{L} / \mathrm{L}$. Fewer females were recorded as the dose was increased to $2000 \mu \mathrm{L} / \mathrm{L}$, while a further decrease was recorded by increasing the dose to $4000 \mu \mathrm{L} / \mathrm{L}$ (Figure 5).

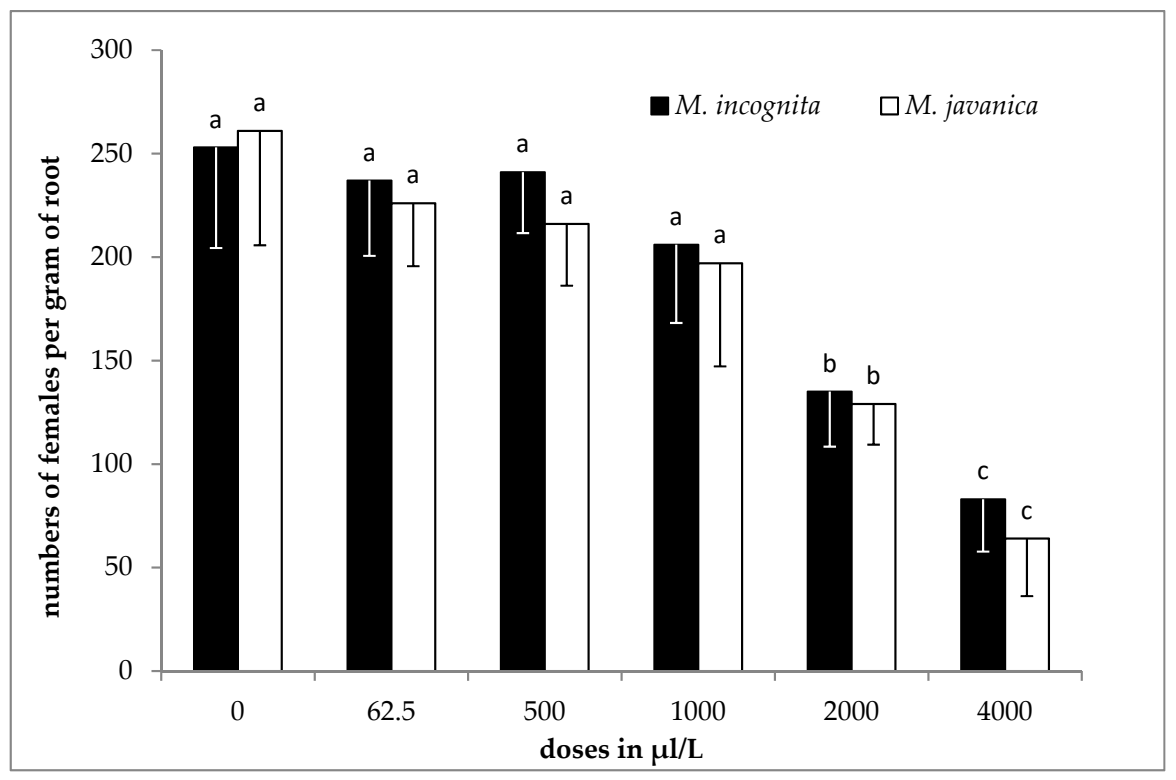

Figure 5. Numbers of females of $M$. javanica and M. incognita per gram of root, after transplanting tomato seedlings in soil treated with essential oil of Satureja hellenica and inoculating with $600 \mathrm{~J} 2 \mathrm{~s}$. Bars with the same color followed by the same letter are not significantly different. Error bars represent the standard deviation of mean. 
Additionally, HL at doses up to $0.1 v / v$ showed no significant differences compared to the untreated control. A significant decrease was observed after increasing the dose to $0.5 v / v$ for both Meloidogyne species tested (Figure 6).

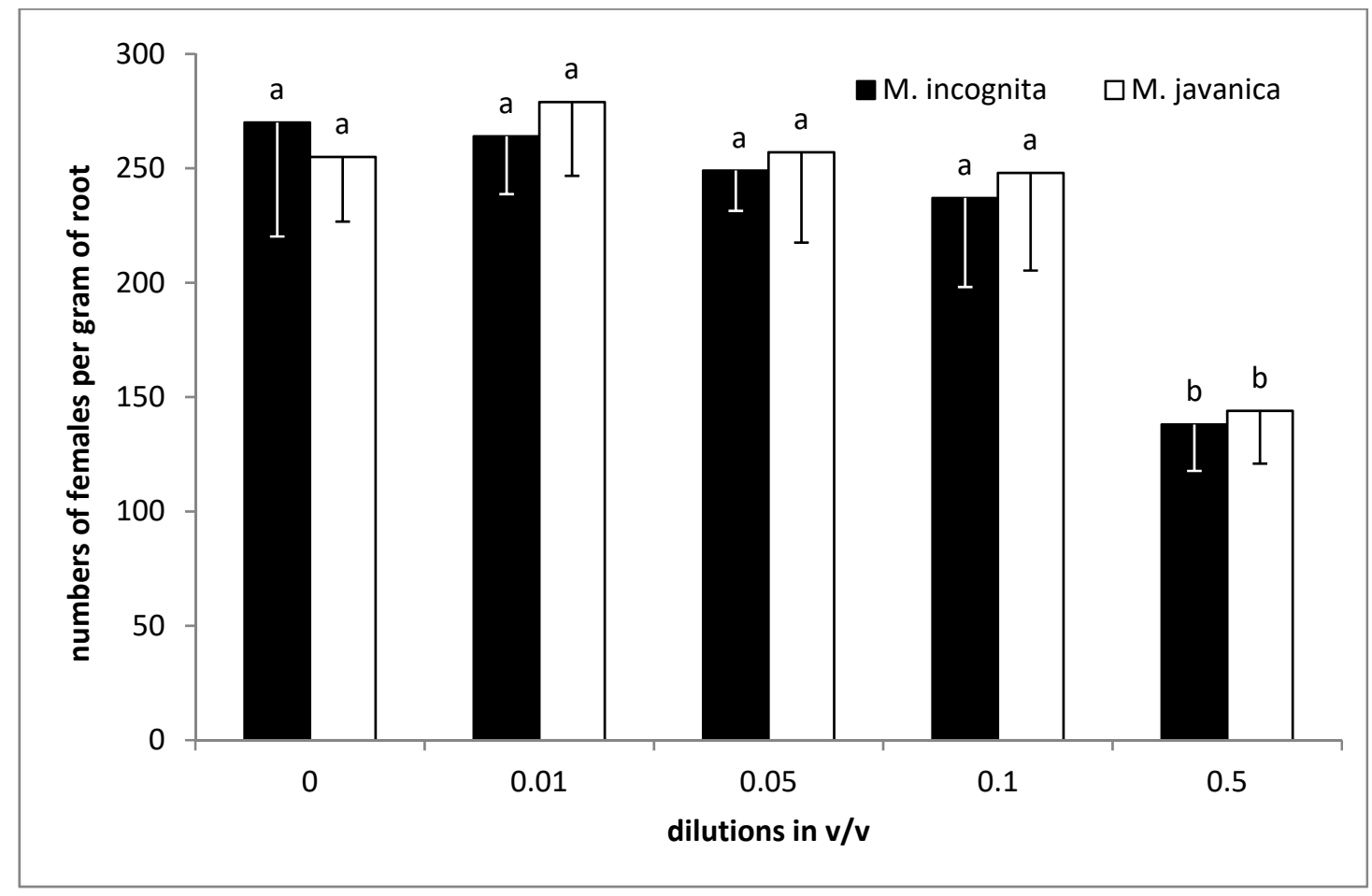

Figure 6. Numbers of females of $M$. javanica and $M$. incognita per gram of root after transplanting tomato seedlings in soil treated with hydrosol of Satureja hellenica and inoculating with $600 \mathrm{~J} 2 \mathrm{~s}$. Bars with the same color followed by the same letter are not significantly different. Error bars represent the standard deviation of mean.

\section{Discussion}

This is the first study to show the toxic effect of Satureja hellenica extracts against Meloidogyne incognita and M. javanica. The essential oil caused a strong effect against the different biological stages of either M. incognita or M. javanica. This study underlines the high nematicidal activity of S. hellenica EO against both species tested. A high percentage of paralyzed J2s was recorded after incubating juveniles for 24, 48 and $96 \mathrm{~h}$. The extracts of Satureja hellenica seem to have a remarkable nematicidal activity against Meloidogyne incognita and M. javanica. The percentages over $80 \%$ of paralyzed J2s, either at the dose of $2000 \mu \mathrm{L} / \mathrm{L}$ in EO, or the dilution of $0.5 v / v$ in hydrosol, after exposure for $48 \mathrm{~h}$ suggested potential efficacy from a control point of view. Increased paralyzed J2s were recorded by increasing either the time of exposure (from 24 to $96 \mathrm{~h}$ ) or the dose of EO. Low doses up to $250 \mu \mathrm{L} / \mathrm{L}$ of EO did not show substantial activity against J2s. However, as the dose was increasing, there was a constant increase in the number of J2s with paralysis. The hydrosol of S. hellenica showed lower activity, and J2s paralysis was always inferior to that observed using EO. Substantial paralysis was only recorded after the immersion of J2s in $0.5 v / v$ dilution for 48 and $96 \mathrm{~h}$.

Satureja hellenica essential oil significantly inhibited egg differentiation. This was noticeable, even at the dose of $250 \mu \mathrm{L} / \mathrm{L}$, but there was not any further increase of inhibition of $M$. incognita eggs as the dose was increasing. When $M$. javanica eggs were exposed to EO, a high percentage of eggs remained undifferentiated at doses of 500 to $4000 \mu \mathrm{L} / \mathrm{L}$. Moreover, lower doses of EO (125 and $250 \mu \mathrm{L} / \mathrm{L})$ have shown a negative effect on egg differentiation. In contrast, the use of S. hellenica hydrosol was not that effective in decreasing egg differentiation, for both species. When hydrosol was tested on the differentiation of eggs, a significant decrease was observed only after increasing the dose to 0.5 
$v / v$. However, at the doses of 0.2 and $0.5 v / v$ in hydrosol, there was a non-significant decrease in the hatching of $\mathrm{J} 2 \mathrm{~s}$ after immersion for 28 days.

Our results show that EO at the two higher doses tested was effective in controlling J2s in soil. Additionally, the hydrosol at the dose of $0.5 v / v$ was effective in reducing the numbers of females in roots almost $50 \%$ compared to the untreated control. However, in field soil infested by root-knot nematodes, there is a reservoir of inoculum remaining from season to season consisted of either J2s or/and eggs free in soil, or protected inside the gelatinous matrix of the egg sac. It has been reported that nematodes' eggs consist of three layers, which act as a barrier against nematicides penetration [21]. It is more accurate to use egg hatching than J2s motility experiments [20]. In our experiments, the essential oil inhibited about 85 and $59 \%$ of the juveniles from hatching, for M. incognita and M. javanica, respectively. Our results on hatching inhibition are in agreement with those reported by Barros et al. [22], who worked with EO isolated from Dysphania ambrosioides having, as a constituent, $p$-cymene. Additionally, EOs from other plant species, containing $p$-cymene and carvacrol as major constituents, have been shown to inhibit nematode hatching $[20,23,24]$. When hydrosol was used, the level of juveniles hatched from egg masses (58 and 49\% for M. incognita and M. javanica, respectively) was lower than that observed in EO. The egg hatch inhibition could be due to the ability of either EO's or HL's to penetrate egg mass and act on nematode eggs [25].

It is obvious from the results of the present study that there are differences in the ratio of terpenes between the EO and the hydrosol. This could explain the differences of activity between the EO and hydrosol extracted from the same plant species. The essential oil of S. hellenica is characterized by both the high presence of monoterpene hydrocarbons (MH) and oxygenated monoterpenes (OM), due mainly to the presence of $p$-cymene, and carvacrol, respectively. The group of $\mathrm{MH}$ did not detect the S. hellenica hydrosol, while the OM occupied $93.7 \%$ of the total composition. The OM exhibited a better extraction to $S$. hellenica hydrosol than the HM, which is explained by the hydrophobicity of the latter. The highest component in the EO is $p$-cymene, which is not present in the hydrosol. On the other hand, the highest constituent of the hydrosol is carvacrol, which is present in EO, but almost $50 \%$ lower than that in the hydrosol. Another terpene, borneol, is present in the hydrosol, almost four times more than in EO. Thymol, which is present in EO but not in hydrosol, has been reported in the literature to be active against root-knot nematodes [26]. The components found in S. hellenica, either in EO or in hydrosol, are reported to have nematicidal properties, either as constituents of aromatic plant species or as isolated terpenes $[25,26]$. However, based on our results, it seems that the ratio of each constituent is very important as far as nematicidal effect is concerned. Our results are in agreement with those from Ntalli et al. [27]. They reported that the EO obtained from O. vulgare and $O$. dictamus contained 68.5 and $44.3 \%$ carvacrol respectively, and had a high nematicidal activity against J2s of M. incognita. Laquale et al. [28] reported a strong action of EOs isolated from two Italian ecotypes of Monarda species. Those essential oils had as constituents, among others, $\gamma$-terpinene and 0 -cymene, which are also present in S. hellenica. It seems that the presence of carvacrol and $p$-cymene as components of EOs are crucial for their nematicidal activity. However, other substances, even in a lesser quantity, might act synergistically, a fact which should be tested.

\section{Materials and Methods}

\subsection{Nematode Populations}

The populations of Meloidogyne incognita and M. javanica were collected from infested tomato greenhouses in Heraklion, Crete, and subsequently reared on tomato seedlings (Solanum lycopersicum L.) cv. Belladona in a glasshouse in Agricultural University of Athens, Greece. All the seedlings were maintained in plastic pots in controlled conditions $\left(25 \pm 2{ }^{\circ} \mathrm{C}, 16 \mathrm{~h}\right.$ light and $8 \mathrm{~h}$ dark). The infestation of the seedlings took place when the plants were 6 weeks old, at the four-leaf stage. After 40 days, roots were collected from plants and washed free of soil. Eggs of Meloidogyne populations were extracted 
using $1 \%$ sodium hypochlorite solution [29]. Second stage juveniles (J2s) were hatched in a modified Baremann funnel, where eggs were placed. The J2s used in all tests were less than 2 days old.

\subsection{Plant Material}

The plants of Satureja hellenica Halásky (Lamiaceae) were collected from the Piges Krias area, near the city of Livadia (Greece). Collected specimens were identified by the fourth author using identification key provided by [30]. The plant material was used to isolate the essential oil and hydrosol used in all trials.

\subsection{Isolation of Essential Oil and Hydrosol and Determination of Their Chemical Composition}

The essential oil was isolated from air-dried leaves and flowers (in the dark, at room temperature) with hydrodistillation (HD), for $3 \mathrm{~h}$ in a $5 \mathrm{~L}$ Clevenger-type apparatus. The essential oil was dried with anhydrous magnesium sulfate $\left(\mathrm{MgSO}_{4}\right)$. The hydrosol was collected in a separate glass bottle. A part of it was extracted by diethyl ether in order to isolate the volatile compounds. The organic phase was dried over anhydrous magnesium sulfate, filtered, and reduced to a final volume. Both essential oil and organic phase were stored in $-18^{\circ}$ until their analysis.

The determination of the chemical composition of the plant isolates was achieved by gas chromatography - mass spectrometry (GC-MS) technique [31], using a trace ultra-gas chromatographer coupled with a DSQ II Mass Spectrometer (Thermo Scientific), fitted with a TR-5MS (30 m $\times 0.25 \mathrm{~mm}$ $\times 0.25 \mu \mathrm{m}$ ) capillary column (Thermo Scientific). The injector and MS transfer line temperatures were set at 220 and $250^{\circ} \mathrm{C}$, respectively. Experimental conditions induced an oven temperature GC programmed from 60 to $250{ }^{\circ} \mathrm{C}$ at a rate of $3{ }^{\circ} \mathrm{C} / \mathrm{min}$. Helium was used as the carrier gas at a $1 \mathrm{~mL} / \mathrm{min}$ flow rate. A quantity of $1.0 \mu \mathrm{L}$ of the diluted samples in the case of EO (1/1000 in acetone, $v / v)$, or of the organic phase, were injected manually in splitless mode. The MS was operating in EI mode at 70 $\mathrm{eV}$; the ion source temperature was $240^{\circ} \mathrm{C}$, whereas mass spectra were acquired in the scan mode for mass range 35-400. Tentative identification of the compounds based on the comparison of their relative retention indices and mass spectra with corresponding data was reported in the literature's and instrument's databases [31]. The relative retention indices (RRI) of compounds were determined with reference to the retention times of $\left(\mathrm{C}_{8}-\mathrm{C}_{24}\right) n$-alkanes. Relative \% percentages of the compounds were obtained electronically from area percentage data.

\subsection{Effect of EO and Hydrosol on J2s Motility}

Cellstar flat bottom 24-well plates were used for all in vitro tests. Solutions of S. hellenica essential oil were tested for J2 motility at the doses of $62.5,125,250,500,1000,2000$ and $4000 \mu \mathrm{L} / \mathrm{L}$. The essential oil was dissolved in ethanol (Sigma-Aldrich; Italy) and serially diluted in distilled water containing Tween-20, to produce test solutions of the above doses. The ethanol and Tween-20 concentrations ( 1 and $0.3 \%$, respectively) were tested in preliminary tests, which showed no effect on nematodes. The hydrosol dilutions (in distilled water) tested for J2s motility were $1 \%(0.01), 2 \%(0.02), 5 \%(0.05)$, $10 \%(0.1) 20 \%(0.2)$ and $50 \%(0.5)(v / v)$. Distilled water was used as a control. Approximately $35 \mathrm{~J} 2 \mathrm{~s}$ were used per treatment well in the plates. Juveniles' suspension $(0.5 \mathrm{~mL})$ and an equal volume of either EO or HL suspension were pipette into each well. All plates were covered with aluminum foil and incubated at $26 \pm 1{ }^{\circ} \mathrm{C}$. J2s observation was conducted using an inverted microscope (100×), after 24,48 and $96 \mathrm{~h}$ incubation time. The juveniles were scored as motile or dead after $10 \mathrm{~s}$ observation and robbing their body with a needle. If there was a lack of movement, the J2s were considered to be paralyzed. Each experiment was conducted twice, and every treatment was replicated five times.

\subsection{Effect of EO and Hydrosol on Egg Differentiation}

Eggs of the two species of nematodes were extracted from tomato (Solanum lycopersicum cv. Belladona) roots, using the hypochlorite method [29]. The suspension of eggs was placed on a $38 \mu \mathrm{m}$ sieve, thoroughly rinsed with tap water and collected into a $100 \mathrm{~mL}$ beaker. The quantification of eggs 
suspension was done using an inverted microscope (100×), and the adjusted suspension was used directly in the bioassays.

Essential oil solutions, at the doses of 62.5, 125, 250, 500, 1000, 2000 and $4000 \mu \mathrm{L} / \mathrm{L}$, and hydrosol dilutions (in distilled water, ethanol and Tween-20) at the concentrations of $0.01,0.02,0.05,0.1,0.2$ and $0.5 v / v$, were tested on the development of eggs. The solutions were prepared as previously described. Distilled water was used as the control. Approximately 50 eggs per well, of which $90 \%$ were undifferentiated, were exposed to either EO or HL solutions and incubated at $26 \pm 1{ }^{\circ} \mathrm{C}$. Egg suspension $(0.5 \mathrm{~mL})$ was pipette into each well, with equal volume of either EO or HL suspension. All plates were covered with aluminum foil to avoid evaporation. For monitoring egg differentiation, eggs were observed on day 0 and day 28, with the aid of an inverted microscope (Zeiss, Germany) at 100× magnification. Eggs were categorized either as differentiated (fully developed juvenile) or undifferentiated (containing only cells). The experiment was conducted twice and each treatment was replicated five times.

\subsection{Hatching Inhibition as Affected by the Presence of EO and Hydrosol}

Mature egg masses of Meloidogyne incognita and M. javanica were handpicked using sterilized forceps from roots free of soil. Egg masses were placed in small plastic extraction trays made by six cm petri dishes. Solutions of S. hellenica essential oil $(62.5,125,250,500,1000$ and $2000 \mu \mathrm{L} / \mathrm{L})$ or hydrosol $(0.01,0.02,0.05,0.1,0.2$ and $0.5 \mathrm{v} / \mathrm{v})$, initially dissolved in ethanol and brought to volume using Tween-20 in water, were added to each extracting tray to cover egg masses. Egg masses were maintained for seven days, and then test solutions were removed by washing them with tap water, and placed in new extracting trays filled with clean water. Extracting trays were covered with aluminum foil to avoid evaporation and placed in an incubator at $26 \pm 1{ }^{\circ} \mathrm{C}$. Hatched J2s were counted every seven days, they were discarded, and the water was substituted with fresh one. The experiment was terminated when J2s did not emerge any longer, 35 days later. Then, the egg masses were picked from Petri dishes, placed in a drop of water on a glass microscope slide, gently squashed between the slide and coverslip, and the number of unhatched eggs per egg mass was counted under an inverted microscope. The experiment was conducted twice and each treatment was replicated five times.

\subsection{Effect of EO and Hydrosol on Juveniles in Soil}

The efficacy of S. hellenica EO and HL against $M$. javanica were evaluated using tomato seedlings, $\mathrm{cv}$ Belladonna. Seedlings at the four-leaf stage grown in soil were collected from a greenhouse at Gargaliani village, Peloponnese. Soil was autoclaved to kill any plant parasitic nematodes. Essential oil solutions, at the doses of 62.5, 500, 1000, and $4000 \mu \mathrm{L} / \mathrm{L}$, and hydrosol dilutions (in distilled water) at the concentration of $0.01,0.05,0.1$, and $0.5 v / v$, were tested on $\mathrm{J} 2 \mathrm{~s}$ in soil. Five plastic pots were filled with the treated soil, and $1 \mathrm{~mL}$ of a suspension containing $500 \mathrm{~J} 2 \mathrm{~s}$ was used for inoculation. Pots were covered with aluminum foil to avoid water evaporation and maintained at $25 \pm 1{ }^{\circ} \mathrm{C}$ for $24 \mathrm{~h}$ to make sure that juveniles came into contact with the chemicals. Then, a tomato seedling (cv Belladonna) at the four-leaf stage was transplanted in the center of each pot. All plants were placed in a growth room at $25 \pm 1{ }^{\circ} \mathrm{C}$ and 28 days later were uprooted, stems were removed, and roots were gently washed free of soil. Roots were stained using acid fuchsin, as described in Byrd et al. [32] Roots were then washed in water and placed in vials containing equal volumes of glycerol and distilled water. Female nematodes were counted in the whole root system of each plant using a stereoscopic microscope at $12.5 \times$ magnification. All treatments were replicated five times, while the experiment was conducted twice.

\subsection{Statistical Analysis}

A one-way analysis of variance (ANOVA) was performed using the general linear model (GLM) in SAS (SAS University Edition). Treatments' means were compared using the Tukey's HSD test 
at $p<0.05$. In case no variation was revealed, the data from two experiments were combined and analyzed together.

\section{Conclusions}

In conclusion, our work showed that S. hellenica extracts can control M. incognita and M. javanica. Our results underlined the paralysis activity against J2s, along with the inhibition of egg differentiation and hatching. However, further experimentation is necessary for the determination of the most efficient rate and dose of these extracts.

Author Contributions: Conceptualization, I.G. and I.P.; methodology, I.G. and D.D.; investigation, I.P. and E.N.; validation, I.G., D.D. and P.T.; formal analysis D.D. and I.G.; writing-original draft preparation I.G. and D.D.; writing-review and editing, I.G., D.D. and P.T. All authors have read and agreed to the published version of the manuscript.

Funding: This research received no external funding.

Acknowledgments: Acknowledgments are due to Emmanouel Tzortzakakis for providing the initial population of Meloidogyne javanica and Meloidogyne incognita. Technical assistance given by the undergraduate student Theodoros Tselios is acknowledged.

Conflicts of Interest: The authors declare no conflict of interest.

\section{References}

1. Bird, D.M.K.; Williamson, V.M.; Abad, P.; McCarter, J.; Danchin, E.G.J.; Castagnone-Sereno, P.; Opperman, C.H. The Genomes of Root-Knot Nematodes. Annu. Rev. Phytopathol. 2009, 47, 333-351. [CrossRef] [PubMed]

2. Bleve-Zacheo, T.; Melillo, M.T.; Castagnone-Sereno, P. The contribution of biotechnology to root-knot nematode control in tomato plants. Pest Technol. 2007, 1, 1-16.

3. Karpouzas, D.G.; Hatziapostolou, P.; Papadopoulou-Mourkidou, E.; Giannakou, I.O.; Georgiadou, A. The enhanced biodegradation of fenamiphos in soils from previously treated sites and the effect of soil fumigants. Environ. Toxicol. Chem. 2004, 23, 2099-2107. [CrossRef] [PubMed]

4. Papadopoulou, E.S.; Lagos, S.; Spentza, F.; Vidiadakis, E.; Karas, P.A.; Klitsinaris, T.; Karpouzas, D.G. The dissipation of fipronil, chlorpyrifos, fosthiazate and ethoprophos in soils from potato monoculture areas: First evidence for the enhanced biodegradation of fosthiazate. Pest Manag. Sci. 2016, 72, 1040-1050. [CrossRef] [PubMed]

5. Akhtar, M.; Mahmood, I. Potentiality of phytochemicals in nematode control: A review. Bioresour. Technol. 1994, 48, 189-201. [CrossRef]

6. Chitwood, D.J. Phytochemical based strategies for nematode control. Annu. Rev. Phytopathol. 2002, 40, 221-249. [CrossRef]

7. Mendoza, A.R.; Kiewnick, S.; Sikora, R.A. In vitro activity of Bacillus firmus against the burrowing nematode Radopholus similis, the root-knot nematode Meloidogyne incognita and the stem nematode Ditylenchus dipsaci. Biocontrol Sci. Technol. 2008, 18, 377-389. [CrossRef]

8. Turatto, M.F.; Dourado, F.D.S.; Zilli, J.E.; Botelho, G.R. Control potential of Meloidogyne javanica and Ditylenchus spp. using fluorescent Pseudomonas and Bacillus spp. Braz. J. Microbiol. 2018, 49, 54-58. [CrossRef]

9. Nyaku, S.T.; Affokpon, A.; Danquah, A.; Brentu, F.C. Harnesing Useful Rhizosphere Microorganisms for Nematode Control, Nematology-Concepts, Diagnosis and Control. Nematol.-Concepts Diagn. Control 2017, 8, 153-182.

10. Andrés, M.F.; González-Coloma, A.; Sanz, J.; Burillo, J.; Sainz, P. Nematicidal activity of essential oils: A review. Phytochem. Rev. 2012, 11, 371-390. [CrossRef]

11. Kabera, J.N.; Semana, E.; Mussa, A.R.; He, X. Plant Secondary Metabolites: Biosynthesis, Classification, Function and Pharmacological Properties. J. Pharm. Pharmacol. 2004, 2, 377-392.

12. Petrakis, E.A.; Kimbaris, A.C.; Lykouressis, D.P.; Polisiou, M.G.; Perdikis, D.C.H. Hydrosols evaluation in pest control: Insecticidal and settling inhibition potential against Myzus persicae (Sulzer). J. Appl. Entomol. 2014, 139, 260-267. [CrossRef] 
13. Traka, C.K.; Petrakis, E.A.; Kimbaris, A.C.; Polisiou, M.G.; Perdikis, D.C. Effects of Ocinum basilicum and Ruta chalepensis hydrosols on Aphis gossypii and Tetranychus urticae. J. Appl. Entomol. 2017, 142, 413-420. [CrossRef]

14. Sadiki, M.; Barkai, H.; Koraichi, S.I.; Elabed, S. The effect of the Thymusvulgaris extracts on the physicochemical characteristics of cedar wood using angle contact measurement. J. Adhes. Sci. Technol. 2014, 28, 1925-1934. [CrossRef]

15. Zengin, H.; Baysal, A.H. Antibacterial and antioxidant activity of essential oil terpenes against pathogenic and spoilage-forming bacteria and cell structure-activity relationship evaluated by SEM microscopy. Molecules 2014, 19, 17773-17798. [CrossRef] [PubMed]

16. Isman, M.B. Plant essential oils for pest and disease management. Crop Prot. 2000, 19, 603-608. [CrossRef]

17. Papachristos, D.P.; Karamanoli, K.I.; Stamopoulos, D.C.; Menkissoglu-Spiroudi, U. The relationship between the chemical composition of three essential oils and their insecticidal activity against Acanthoscelides obtectus (Say). Pest Manag. Sci. 2014, 60, 514-520. [CrossRef]

18. Abdel-Rahman, F.H.; Alaniz, N.M.; Saleh, M.A. Nematicidal activity of terpenoids. J. Environ. Sci. Health. 2013, 48, 16-22. [CrossRef]

19. Park, I.K.; Kim, J.; Lee, S.G.; Sheen, S.C. Nematicidal activity of plant essential oils and components from ajowan (Trachysperum ammi), allspice (Pimenta dioica) and litsea (Litsea cubeba) essential oils against wood nematode (Bursaphelenchus xylophilus). J. Nematol. 2007, 39, 275-279.

20. Oka, Y.; Nacar, S.; Putievsky, E.; Ravid, U.; Yaniv, Z.; Spiegel, Y. Nematicidal activity of essential oils and their components against the root-knot nematode. Phytopathology 2000, 90, 710-715. [CrossRef]

21. Moens, M.; Perry, N.P.; Starr, L.J. Root-Knot Nematodes; CAB International: Wallingford, UK, 2009.

22. Barros, A.F.; Campos, V.P.; De Paula, L.L.; Oliveira, D.F.; De Silva, F.J.; Terra, W.C.; Silva, G.H.; Salimena, J.P. Nematicidal screening of essential oils and potent toxicity of Dysphania ambrosioides essential oil against Meloidogyne incognita in vitro and in vivo. J. Phytopathol. 2019, 167, 380-389. [CrossRef]

23. Jeon, J.H.; Ko, H.R.; Kim, S.J.; Lee, J.K. Chemical composistion and nematicidal activities of essential oils on Meloidogyne hapla (Nematode: Tylenchida) Under Laboratory Conditions. Korean J. Pest. Sci. 2016, 20, 30-34. [CrossRef]

24. Faria, J.M.S.; Sena, I.; Ribeiro, B.; Rodrigues, A.M.; Figueiredo, A.C.S. First report on Meloidogyne chitwoodi hatching inhibition activity of essential oils and essential oils fractions. J. Pest Sci. 2016, 89, 207-217. [CrossRef]

25. Nasiou, E.; Giannakou, I.O. The potential use of carvacrol for the control of Meloidogyne javanica. Eur. J. Plant Pathol. 2017, 149, 415-424. [CrossRef]

26. Nasiou, E.; Giannakou, I.O. Effect of geraniol, a plant-based alcohol monoterpene oil, against Meloidogyne javanica. Eur. J. Plant Pathol. 2018, 152, 701-710. [CrossRef]

27. Ntalli, N.G.; Ferrari, F.; Giannakou, I.; Menkissoglu-Spiroudi, U. Phytochemistry and nematicidal activity of the essential oils from 8 greek lamiaceae aromatic plants and 13 terpene components. J. Agric. Food Chem. 2010, 58, 7856-7863. [CrossRef]

28. Laquale, S.; Avato, P.; Argentini, M.P.; Bellardi, M.G.; D'Addabbo, T. Nematotoxic activity of essential oils from Monarda species. J. Pest Sci. 2018, 91, 1115-1125. [CrossRef]

29. Hussey, R.S.; Barker, K.R. A comparison of methods of collecting inocula of Meloidogyne spp., including a new technique. Plant Dis. Rep. 1973, 57, 1025-1028.

30. Dardioti, A. Biosistimatiki Meleti tis Omadas Satureja Montana L. stin Ellada [Biosystematic study of Satureja Montana L. Group in Greece]. Ph.D. Thesis, Aristotle University of Thessaloniki, Thessaloniki, Greece, 4 July 2005.

31. Adams, R.P. Identification of Essential Oil Components by Gas Chromatography/Mass Spectrometry, 4th ed.; Allured Publ. Corporation: Carol Stream, IL, USA, 2007.

32. Byrd, D.W.; Krickpatrick, T.; Barker, K.R. An improved technique for cleaning and staining plant tissue for detection of nematodes. J. Nematol. 1983, 15, 142-143.

(C) 2020 by the authors. Licensee MDPI, Basel, Switzerland. This article is an open access article distributed under the terms and conditions of the Creative Commons Attribution (CC BY) license (http://creativecommons.org/licenses/by/4.0/). 